\title{
Remote Sensing of SAlinity IN THE COASTAL ZONE
}

\author{
By Jerry Miller
}

\begin{abstract}
A POR PROBLEM in coastal oceanography is the lack of knowledge of the spatial and temporal scales at which water masses of various origins interact within the coastal zone. While their gross characteristics may be known, the smallscale, two-dimensional, horizontal variability of water mass properties cannot be adequately determined using conventional oceanographic measurement methods. Typically, these small-scale variations are measured in one dimension, if at all, using conventional techniques and usually at great expense. Thus many key parameters necessary for the characterization and quantification of important physical, chemical, and biological processes in the coastal and estuarine regions remain unknown. A prototype instrument that promises to remedy this situation for the parameter which most influences
\end{abstract}

J. Miller, Center for Coastal Physical Oceanography, Old Dominion University, Norfolk, VA 23529. the hydrodynamics of runoff-influenced coastal regions (i.e., salinity) is now available.

This instrument, the Scanning Low Frequency Microwave Radiometer (SLFMR), was produced by Quadrant Engineering under a NOAA SBIR contract. The SLFMR is an imaging sensor which provides complete areal coverage of surface salinity in a swath roughly twice as wide as the aircraft's altitude. Since the swath is resolved into several adjacent cells and swaths can be quickly flown adjacent to each other, the SLFMR can provide spatially continuous high-resolution data in a synoptic manner. It is designed to be flown on small inexpensive aircraft and, therefore, represents the first opportunity for the coastal oceanographic community to obtain highresolution imagery of relevant physical quantities on a routine basis and in a synoptic fashion. Current plans call for the SLFMR to be flown over Florida Bay during 1995 to examine effects of runoff from the Everglades and/or hypersaline conditions during times of high evaporation. 